\title{
MANAGEMENT OF DENTAL RADIOGRAPHIC WASTE
}

\author{
Jyothirmai Koneru', Neha Mahajan², Mallika Mahalakshmi ${ }^{3}$
}

${ }^{1}$ Senior Lecturer, Department of Oral Medicine and Radiology, Noorul Islam College of Dental Sciences, Trivandrum, Kerala.

${ }^{2}$ Senior Lecturer, Department of Oral Medicine and Radiology, Institute of Dental Sciences, Sehora, Jammu.

${ }^{3}$ Reader, Department of Oral Medicine and Radiology, Mamata Dental College, Khamam, Andhra Pradesh.

\begin{tabular}{l|l}
\hline ABSTRACT \\
$\begin{array}{l}\text { Radiographs are used by the dentists for the diagnosis, and/or treatment of patients in the majority of the } \\
\text { cases. These radiographs have become a third eye to the dentist. Even with the advent of digital imaging there } \\
\text { are a large number of dental offices that use conventional methods to obtain the radiographic images. } \\
\text { Unfortunately, the conventional radiographic procedures generate certain substances that present as potential } \\
\text { challenge to the environment. Although individual dentists generate only small amount of environmentally } \\
\text { hazardous wastes, the accumulated waste produced by the profession may have a significant environmental } \\
\text { impact, which in turn may pose a risk to the human health. Thus, it becomes extremely important for the } \\
\text { proper disposal of materials originated from conventional radiographic methods, in order to minimize the } \\
\text { negative environmental impact. This paper addresses the environmental impact of dental radiographic waste } \\
\text { and describes measures that can be taken by dentists and their team to reduce the production of potentially } \\
\text { harmful wastes. }\end{array}$
\end{tabular}

Key words: Dental,Film, Lead, Radiographic waste, Silver

\section{INTRODUCTION}

The discovery of $x$ rays has revolutionized the field of medicine and in turn, dentistry. Radiographs are used by the dentists for the diagnosis and/or treatment of patients in the majority of the cases. These radiographs have become a third eye to the dentist. In spite of the advances in the imaging modalities there are still many dentists who practice the conventional methods to obtain the radiographic images. Basically, the conventional technique performed to obtain the radiographic images comprises of the exposure of radiographic films to $x$ rays, followed by the processing of the films. This traditional processing procedure involves the steps of image developing, washing, fixing, final washing and drying. ${ }^{1}$ Unfortunately, these radiographic procedures generate certain waste substances that present a potential challenge to the environment. Examples of such waste materials include used x-ray processing solutions, processor system cleaners, lead foil, used/ unused dental films. In addition to the waste generated by the conventional processing, lead aprons, lead shields and non functioning $\mathrm{x}$-ray units are also considered waste when they reach their end life. Although individual dentists generate only small amounts of these environmentally hazardous wastes, the accumulated waste produced by the profession may have a significant environmental impact which in turn may pose a risk to the human health. ${ }^{2}$

The liquid hazardous wastes if discharged into a sewer system, can potentially impact the waste water treatment plant, and/or pass through the treatment plant into the bay, ocean, river, or other receiving waters. Alternatively, if materials are disposed of in the trash, they may eventually contaminate the soil, ground water, or create a public health problem. Most radiographic waste generated in the dental office can be managed as non-hazardous waste, if proper disposal guidelines are followed. For example, lead waste can be recycled, as can silver-containing waste; and liquid developer that is slightly basic can be disposed down the drain if local $\mathrm{pH}$ limits are not exceeded. ${ }^{3}$ Most of the dentists are unaware of the harmful effects of the 
radiographic waste and some neglect it thinking the waste generated by them is negligible. This paper addresses the environmental impact of dental radiographic waste and describes measures that can be taken by dentists and their team to reduce the production of potentially harmful wastes.

\section{LEAD WASTE}

The lead waste has the major impact on the environment compared to the other dental radiographic waste. The lead containing products used in dentistry are lead foils, shields and aprons.

Lead foil is used in intraoral films to protect the film from backscatter and secondary irradiation. The lead content of this foil is $69 \%$ to $85 \%$. Most of the dentists prefer to discard the lead foil in the common garbage, thinking of the small amount of examinations they performed. ${ }^{1}$ Based on data from the studies of Tsuji et $\mathrm{al}$, as much as $11.2 \mathrm{~g}$ of lead waste would be produced in the course of examining of one new patient with full mouth radiographs. The lead contained in the foil can be leached from the landfills if no leachate collection system is in place. During the anaerobic acid subphase of the degradation process, microorganisms break down organic material, producing organic acids such as acetic acid which results in a drop in $\mathrm{pH}$. This acidic $\mathrm{pH}$ can cause significant dissolution of lead from the radiographic foil in only 17 hours. Thus lead enters the ecosystem. ${ }^{4}$ It has been found out that there is no safe level of exposure to lead and it is toxic even at low exposures. Lead poisoning in adults can affect the peripheral and central nervous systems, the kidneys, blood pressure and reproductive systems. Children are more sensitive to lead than adults as the exposure is increased by their hand-to-mouth activity with their gut absorbing lead more readily than an adult. The developing CNS is more vulnerable to toxicants than the mature CNS. ${ }^{5,6}$

According to a study done by Carvalho et al, ${ }^{1}$ more than $72 \%$ of dentists reuse the lead foils for bite registration, which put at risk the patient's health, as lead can be easily dissolved by human saliva. Additionally, some of the dentists or the supporting staff does not wash their hands or change their gloves after processing intraoral films. Lead oxide might adhere to the gloves or hands and can be introduced onto instruments and dental paraphernalia used in the mouths of patients. Dental films stored in certain leadlined film containers instead of lead painted or coated were also identified as a potential source of lead exposure for patients and practitioners because of a white layer of approximately $80 \%$ lead that covered the dental film. ${ }^{4}$

Reducing environmental lead contamination by dentists is an easy and inexpensive task. The lead foil from film packets has to be collected and returned back to the manufacturer for recycling. The only expense would be for postage. It appears that there is a lack of awareness among the dentists about this service offered by the manufacturers as manufacturing companies report that only about $5 \%$ of products sold are returned. ${ }^{2,7}$ Even the lead aprons and lead shields should not be thrown into the regular garbage and they should be returned to the manufacturer. ${ }^{3,8}$

\section{X-RAY FILM PROCESSING WASTE}

Dental hospitals that operate conventional imaging use chemicals like developer, fixer, and equipment cleaner. Each of these chemical solutions is unique and requires special handling and disposal procedures. ${ }^{3}$

\section{Developer}

Used developer is not typically a hazardous waste because of its low silver content (usually below the regulatory level of $5 \mathrm{mg} / \mathrm{l}$ silver) and lack of other constituents or characteristics that would make it hazardous waste. Developer solutions are caustic in nature, i.e., they have a high $\mathrm{pH}$ of approximately 10 . So, the waste developer may be flushed down the drain, as long as the $\mathrm{pH}$ of the solution does not exceed the $\mathrm{pH}$ standard of the local public waste water treatment authority. It is always better to check with the local sewer authority before disposing.

Dental hospitals that are on individual septic disposal systems should not pour this material down the drain because developer solutions are composed of aromatic phenolic compounds and amino acid salts whose chemical oxygen demand is high and the products of its reactions can harm the septic system. They should contract with an industrial waste water disposal company for disposal of these wastes. ${ }^{1}$

\section{Fixer}

Fixer solutions remove approximately $35-45 \%$ of the undeveloped silver halide compounds from the film emulsion, depending on the object exposed. ${ }^{9}$ Spent $\mathrm{x}$ ray fixer contains high levels of silver that is mostly in the form of silver thiosulphate complexes, which are extremely stable and have low dissociation constants. 
There are virtually no free silver ions in used fixer solution. Waste water treatment processes convert silver thiosulphate to silver sulfide which settles in the sludge. In an aquatic life toxicity study using fathead minnows, it was found that silver thiosulphate was more than 17,500 times less toxic and silver sulfide was more than 15,000 times less toxic than free silver ions. So silver in fixer solutions, has little adverse environmental effect. However, sewer authorities in some areas impose limits on silver in waste water and in some cases mandate pretreatment. ${ }^{10,11}$

Silver from used fixer is a valuable resource that should be recycled. There are two basic management options for fixer: (1) on-site treatment and disposal; or (2) offsite treatment and disposal. Whether treated on-site or off-site, silver is easy and economically recyclable and recycling is the preferred method of managing., ${ }^{3,12}$

If the practice generates only small quantities of fixer, it may be more cost-effective and efficient to have the fixer transported off-site for silver removal. By opting for off-site disposal, $100 \%$ recovery of silver in x-ray fixer is guaranteed. It can be transported to a silver reclaiming facility or the manufacturers or distributors of fixer solutions. Some have the "take back" policy for solutions purchased from them. When storing fixer for off-site treatment or disposal, remember to collect and store the fixer in a closed plastic container. Label the container "Used fixer" along with the date when fixer was first added to the container. ${ }^{10}$

On site recovery of silver from the fixer is done by using either metallic replacement or electroplating methods. ${ }^{15}$ Metallic replacement uses cartridges through which silver containing used fixer solutions is poured. The silver in solution and the solid metal (iron) interact and the more active metal (iron) goes into solution. The less active metal, then becomes solid (silver sludge), which settles to the bottom of the cartridge. In the electroplating method, the waste solutions come in contact with two electrodes, through which a current passes. The cathode captures the silver. In either case, the scrap silver can be sold to silver refiners and buyers. ${ }^{10,13}$

On-site silver recovery is often an expensive alternative to off-site treatment unless the practice generates large amounts of radiographic films, but can be considered when there is no off-site disposal system in order to comply with the local sewer authority regulations.

\section{Dental Film}

Unused film should not be placed in the general waste as it contains unreacted silver that can be toxic in the environment. Even used dental films which are kept in the hospital records for 5-10 years, depending on the individual hospital policy should not be discarded in common garbage. These used dental films may contain sufficient amounts of silver depending on the object it was exposed. More the dark areas in the film more will be the silver content. So these used and outdated or improperly stored unused films can be safely disposed by simply contacting the supplier of the product and returning the waste for recycling. Alternatively, a certified waste carrier can be contacted to dispose of the waste, ideally by recycling. ${ }^{8}$

\section{X-Ray system cleaners}

Many cleaners used for automatic processors contain chromium, which is hazardous waste when discarded. As an alternative, it is easier and cheaper to use a system cleaner that does not contain chromium. ${ }^{3}$

\section{Non functioning $x$-ray units}

While managing a non functioning $x$-ray unit, the manufacturer of an x-ray unit will take responsibility, if contacted, when it reaches end-of-life. Where an old $\mathrm{x}$-ray unit is replaced with a new unit, the manufacturer of the new unit provides the free take back of the old $\mathrm{x}$-ray unit, and finances its environmentally sound management, irrespective of the brand of the old unit or the brand of the new unit being supplied.

\section{CONCLUSION}

Dentists have moral and professional responsibility towards dental as well as the general health of patients they care. This should extend beyond the radiation safety procedures normally adopted within the dental office to a more generalized consideration of the environmental impact of the potentially hazardous waste products from these procedures. The preferred solution is to shift to digital $\mathrm{x}$-ray systems which replace the film based technology with the computer based devices that use electronic or storage phosphor receptors to record the radiographic image in digital format. This eliminates the wastes associated with conventional film processing along with many more advantages like less time consuming and image manipulation. The only waste that would be generated by the digital systems is when those systems reach 
their end life. They can be effectively managed by sending back to the manufacturer of the product. So, the dentist should take up the responsibility to save the environment by proper waste disposal while using the conventional imaging and shift to digital imaging as early as possible.

\section{References}

1. Silva MAS, Santos-Neto OS, Amorim JM \& Bauer J. Evaluation of radiographic waste management in dental offices and radiology clinics of São Luís (MA). RSBO 2012;9:260-5.

2. Hiltz M. The Environmental Impact of Dentistry. JCDA 2007;73:59-62.

3. Sushma R, Naganandini S \&Nagabhushana D.Issues Impacting Dental Hospital Waste. Indian J Dent Adv 2012;4:814-21.

4. Tsuji LJS, Wainman BC, Jayasinghe RK, Spronsen EV \& Nieboer E. Foil Backing Used in Intraoral Radiographic Dental Film: A Source of Environmental Lead. J Can Dent Assoc, 2005;71:35-8.

5. Needleman H. Lead Poisoning. Annu. Rev. Med 2004;55:209-22.

6. Thacker SB, Hoffman DA, Smith J, Steinberg K \& Zack M.
Effect of low level body burdens of lead on the mental development of children: limitations of meta-analysis in a review of longitudinal data. Arch Environ Health 1992;47:336-46.

7. Swanson RL, Roethel FJ \&Bauer H. Reuse of lead from dental X-rays. NY State Dent J 1999;65:34-6.

8. Muhamedagic B, Muhamedagic L\& Masic I. Dental Office Waste - Public Health and Ecological Risk. Mater Sociomed 2009;21:35-8.

9. Khunprasert P, Grisdanurak N, Thaveesri J, Danutra V\& Puttitavorn W. Radiographic film waste management in Thailand and cleaner technology for silver leaching. Journal of Cleaner Production, 2008;16:28-36.

10. ADA council on scientific affairs. Association Report. Managing silver and lead waste in dental offices J Am Dent Assoc 2003;134:1095-6.

11. Grigoletto JC, Segura-Munoz SI, Barbosa-Jr F, Sanches SM \& Takayanagui AM. Silver discharged in effluents from image-processing services: a risk to human and environmental health. Biological trace element research 2011;144:316-26.

12. Anderson K. Creating an environmentally friendly dental practice. CDS Rev 1999;12-8.

13. Pharoah $\mathrm{M}$, White SC, eds.Oral radiology: principles and interpretation, 6th edn:Mosby; St. Louis, Missouri.2009. 